\title{
Analytics of Preowned Cars
}

\author{
Divya Agarwal $^{1}$, Arpita Ganguly ${ }^{2}$, Sahil Arora ${ }^{3}$, Arati Kharat ${ }^{4}$ \\ Student (BE), Computer, MITAOE, Pune, India ${ }^{1,2,3,4}$
}

\begin{abstract}
Budget Pre-Owned Cars is built with a vision that there has to be a better way to buy and sell a pre-owned car, A memorable one every customer leaves with. This includes: 1 . Better selection of high quality of cars. 2. Low prices and after sales services. 3. A stress free experience. 4. No-obligation deal of purchase or sale. 5. No-pressure customer service. And therefore we intend to make analytics for the following ideas: 1. Price prediction 2. Sales Prediction 3. Customer parameters 4. Payment support 5. Customer segmentation 6. Future services. Data analytics will help in separating useful information from the useless data. Also, it can save the company time and minimize error rates, hence improved accuracy and quality. These insights will hence further help in modifying the products according to the market needs. These predictions are based on the historical data; hence die rent techniques will be used including data mining for the same. The predictions are then evaluated and compared to and the one with best performance.
\end{abstract}

Keywords: Data mining, Data analytics, Prediction, Information filtering, commercial services.

\section{INTRODUCTION}

This system defines the Way of recommendation based on the previous car of the user and user can determine the Next recommended car will be bought. The recommendation is based on the feedback and reviews of the product which is given by the user. The analysis is dependent on the review and feedback. It will generate the analysis report and Graph of same. India being the second most populated country in the world and the growth rate of Indian economy is also high as compared to developed countries, which attracts the presence of huge demand in the Automobile Small Car Industry. India is becoming emerging market for worldwide auto giants. India is on growth path and has lowest passenger vehicle penetration. For most of the people, purchasing a car is the second most important and expensive decision, next to purchase of a house; for the automotive manufacturers, first-time car buyers give them the opportunity to create positive brand image which definitely could be reflected in next coming years because consumers can make previously owned \&used car. The concept of "buying behaviour" is of prime importance in marketing and has evolved over the years. It is very important to understand consumer buying behaviour as it plays a vital role while purchasing products.

This lead to constant modifications of Car Models and its features in terms of their size, capacity, styling etc. and today we see a new model coming into the market practically every quarter. Market has become very competitive and has become very 'important place' to study the behaviour of consumers and also provide useful insights what a consumer requires in a product in a constant dynamic environment. Consumer behaviour also differs for same Car. Consumer behaviour is fairly complex as Car Purchase implies a high level of social and psychological involvement. Consumer buying behaviour is a blend of Economic, technological, political, cultural, demographic and natural factors as well as Customer's

own characteristics which is reflected by his attitude, motivation, perception, personality, knowledge and lifestyle.

\section{PURPOSE}

This recommendation system is based on the feedback and reviews of the product. This system analyse the feedback and review of the products. Then system generates the report and graph on the basis of the feedback and review of the product.

\section{III.METHODOLOGY}

NATURAL LANGUAGE PROCESSING: NLP for short in a wide sense to cover any kind of computer manipulation of natural language. At one extreme, it could be as simple as counting word frequencies to compare different writing styles. At the other extreme, NLP involves "understanding" complete human utterances, at least to the extent of being able to give useful responses to them. Technologies based on NLP are becoming increasingly widespread. For example, phones and handheld computers support predictive text and handwriting recognition; web search engines give access to information locked up in unstructured text; machine translation allows us to retrieve texts written in Chinese and read them in Spanish. By providing more natural human-machine interfaces and more sophisticated access to stored Information, language processing has come to play a central role in the multilingual information society.

Parts of Speech Tagging (POS): In this task, text is split up into different grammatical elements such as nouns and verbs. This is useful in analyzing the text further. Sentiment analysis: People's feelings and altitudes regarding movies, books, and other products can be determined using this technique. This is useful in 
providing automated feedback with regards to how well a product is perceived.

Tokenization: When we Tokenize text, it usually means we are breaking up the text into a sequence of words. These words are called Tokens. Process is referred to as Tokenization. When a language uses whitespace characters to delineate words, this process is no too difficult. With a language like Chinese, it can be quite difficult since it uses unique symbols for words. Words and morphemes may need 10 be assigned a part Of speech label identifying what type of unit it is. A Morpheme is the smallest division of text that has meaning. Prefixes and suffixes are examples of morphemes. Often, we need to consider Synonyms, abbreviation, acronyms, and spellings when we work with words.

Stemming: Stemming is another task that may need to be applied. Stemming is the process of finding the word stem of a word. For example, words such as "walking", "walked" or "walks" have the word stem "walk". Search engines often use stemming to assist in asking a query

\section{IV.ARCHITECTURE OF PROJECT}



- Recommendation of cars to users

- Analytics based on the user review and Feedback

\section{CONCLUSION}

This recommendation system is based on the feedback and reviews of the product which is given by the user. The previous car of the user and can determine the Next recommended car will be buy. The analysis is dependent on the review and feedback. This system generates the feedback and reviews analysis report and graph.

\section{REFERENCES}

[1] Manish Kumar Srivastava, A.K Tiwari, A Study of Behaviour of Maruti SX4 and Honda City Customers in Jaipur, Pacific Business Review- Quarterly Referred Journal.

[2] M.Prasanna Mohan Raj, Jishnu Sasikumar, S.Sriram, A Study of Customers Brand Preference in SUVS and MUVS: Effect on Marketing Mix Variables, International Referred Research Journal Vol.- IV, Issue-1, pp. 48-58, Jan 2013.

[3] Samin Rezvani, Goodarz Javadian Dehkordi, Muhammad Sabbir Rahman, A Conceptual study on the country of origin effect on consumer purchase intention, Asian Social Science Vol. 8, No.12, 2012 pp. 205-215.

[4] P Sankaran, Indian Automobile industry vision 2020.

[5] Auomotive mission plan 2006-2016, "ministry of heavy industries and public enterprises"- Government Of India.

[6] M. Prasanna Mohanraj, Jisnu Sasi Kumar, S. Sriram, A study of customers brand preference in SUVS and MUVS: Effect on marketing mix variables, International Reffered Research journal Vol.- IV, Issue-1,pp. 48-58,Jan 2013.

[7] International Journal of scientific and research publications, Volume 4, Issue 2, February 2014, ISSN 2250-3153.

[8] Stuart Sinclair (1983) Future of automobile industry Euro monitor publications Ltd. Doughty Street, London.

\section{BIOGRAPHY}

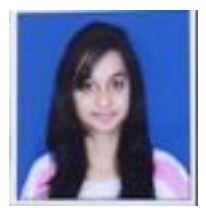

Divya Agarwal pursuing her BE Graduation degree from MITAOE, Pune University, India in 2017.

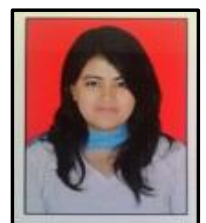

Arpita Ganguly pursuing her BE Graduation degree from MITAOE, Pune University, India in 2017.

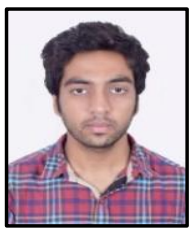

Sahil Arora pursuing his BE Graduation degree from MIT-AOE, Pune University, India in 2017.

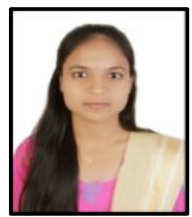

Arati Kharat pursuing her BE Graduation degree from MIT-AOE, Pune University, India in 2017. 